\title{
Localización de la inf raestructura católica, dinámicas socioterritoriales y geografía de las religiones: el caso del Área Metropolitana de Santiago de Chile
}

Rodrigo Hidalgo. Pontificia Universidad Católica de Chile, Santiago, Chile. Federico Arenas. Pontificia Universidad Católica de Chile, Santiago, Chile. Abrabam Paulsen. Pontificia Universidad Católica de Chile, Santiago, Chile. Tania Timofeew. Pontificia Universidad Católica de Chile, Santiago, Chile. Paloma Henríquez. Pontificia Universidad Católica de Chile, Santiago, Chile.

RESUMEN | Entre 2008 y 2009, un equipo de investigadores del Instituto de Geografía de la P. Universidad Católica de Chile abordó el estudio de las formas cómo la Iglesia católica se relaciona y contribuye con el dibujo del paisaje socioespacial en el Área Metropolitana de Santiago. Lo hizo mediante el análisis e interpretación de la localización de los edificios católicos, la base socioeconómica de los habitantes que habitan en dichos lugares, la variación intercensal del número de católicos entre los años 1992 y 2002 y los fundamentos de dicha Iglesia a lo largo de los años para la localización de su infraestructura. En forma específica, los objetivos de la investigación fueron localizar y espacializar los edificios católicos, caracterizar y analizar la población católica por comuna para el período 1992-2002, y conocer los lineamientos de la institución católica sobre la localización de sus edificios.

PALABRAS ClAVE | Desigualdad social, fragmentación urbana, transformaciones socioterritoriales

ABSTRACT | Between 2008 and 2009, a team of researchers from the Institute of Geography of the Pontificia Universidad Católica de Chile studied the ways in which the Catholic Church relates itself and contributes to the drawing to the sociospatial landscape in Santiago's Metropolitan Area. It did so by the analysis and interpretation of the localization of Catholic buildings; the socioeconomic base of the inhabitants of those areas; the intercensal variation of the number of Catholics between the years 1992 and 2002; and the founding concepts of that Church in the localization of its infraestructure through the years. Specifically, the objectives of the investigation were to locate and spatialize the Catholic buildings, to characterize and analyze the Catholic population for the 1992-2002 period and to know the guidalines of the Catholic institution for the location of its buildings.

KEY WORDS | Social inequality, urban fragmentation, socio-territorial transformations

Recibido el 22 de junio de 2010, aprobado el 30 de mayo de 2011

E-mail: Rodrigo Hidalgo, hidalgo@geo.puc.cl | Federico Arenas, farenasv@uc.cl | Abraham Paulsen, apaulsen@uc.cl | Tania Timofeew, timofeew@geo.puc.cl | Paloma Henríquez, phenriquez@geo.puc.cl

Este artículo es parte de los resultados finales del Proyecto de Investigación "La Iglesia dibuja la ciudad: dinámicas socioterritoriales de las parroquias en la región Metropolitana”, que contó con el apoyo de la Vicerrectoría Adjunta de Investigación y Doctorado y de la Dirección General Pastoral de la Pontificia Universidad Católica de Chile. 


\section{Introducción}

La geografía de la religión y el estudio geográfico de las religiones han estado presentes desde los inicios de la ciencia (Dando, 2009; Warf \& Vincent, 2007), ya que la religión es una categoría fundamental en la vida individual y social, parte de las relaciones de poder imperantes al interior de las formaciones sociales, y también de la identidad de las colectividades. Su estudio geográfico revela en qué medida la localización de los templos y/o edificaciones religiosas da cuenta de los objetivos que cada congregación persigue en materia de evangelización, considerando que cada grupo religioso orienta su oferta a la captación de posibles interesados al interior de la ciudad.

Tanto en lo concerniente a la religión como a la diversidad religiosa, algunas disciplinas - entre ellas la sociología de las religiones, la geografía cultural y la geografía de las religiones - las estudian desde el enfoque weberiano. En particular, aplican la teoría de la secularización, entendiendo la diversidad como una consecuencia del decrecimiento de la hegemonía de un credo específico en la vida de un grupo social específico (Berger, 2005). Otros enfoques asocian la diversidad a la necesidad individual y grupal de reemplazar relaciones sociales fundamentales que estarían debilitándose (relaciones familiares, cantidad de amigos, etcétera), por instancias donde los individuos a lo menos comparten una identidad religiosa común (Warf \& Vincent, 2007, p. 601). Espacialmente hablando, la diversidad religiosa ha sido objeto de estudios recientes (aun cuando también ha formado parte de estudios sociales y geográficos clásicos); se han investigado las posibles relaciones entre la distribución geográfica de los credos, el crecimiento económico, la estructura institucional de los credos, los derechos de las mujeres, la difusión de las ciencias y/o modalidades (objetivos, paradigmas) en educación, gobernanza, guerras y conflictos, las fuerzas que originan los diferentes paisajes religiosos, entre otros temas (Warf \& Vincent, 2007, p. 598).

En materia de la geografía de las religiones, Pierre Gourou (1936) fue quien primero las incorporó en el estudio de los géneros de vida, al analizar cómo el comportamiento humano era mediado por la religión en células sociales elementales y cómo esas conductas se expresaban espacialmente. Este modelo analítico fue seguido por Deffontaines, Planhol y Sopher, entre otros (Flores, 2007).

Otra posibilidad que otorga la geografía cultural es estudiar, más que las relaciones económicas entre diversos actores e instituciones, el consumo en toda su complejidad y en todos los efectos territoriales que genera. Es posible también examinar las representaciones espaciales, las relaciones entre identidad y territorio, las dinámicas de las alteridades en los escenarios urbanos, los procesos de exclusión y segregación socioespacial, los espacios religiosos y sagrados, entre otros aspectos. En este marco, las demandas religiosas pueden ser abordadas como un tipo especialísimo de consumo (Flores, 2007).

En el caso de Chile, el estudio de las relaciones de los fieles con el territorio es relevante en el sentido de que el desarrollo histórico del sistema urbano chileno ha 
estado marcado por la fuerte presencia católica desde los tiempos del higienismo, e incluso mucho antes. En tiempos de la conquista y evangelización, las parroquias servían en ocasiones como punto de partida para la fundación de villas y ciudades, convirtiéndose en sitios de referencia indispensable de los centros poblados. Las parroquias son la presencia concreta de la Iglesia en el territorio colonial, centro de la unidad religiosa y, al mismo tiempo, bases de la unidad social. La Iglesia ha actuado en el curso de las décadas como un agente urbano, insertándose en las formas de vida de los habitantes y dibujando la ciudad (Centro de Investigaciones Socioculturales [Cisoc]-Bellarmino, 1999).

Las relaciones Iglesia-Ciudad se han ido modificando con el correr de las décadas, así como se ha ido generando el cambio social de la modernidad. Es en este punto donde se inserta este estudio, que quiere identificar las tendencias y patrones que han seguido los habitantes de la ciudad en su relación tanto con la Iglesia como con el espacio urbano. Para ello se entiende la parroquia, de acuerdo con el Código de Derecho Canónico (1983), como "una determinada comunidad de fieles constituida de modo estable en la Iglesia particular, cuyo cura pastoral, bajo la autoridad del Obispo diocesano, se encomienda a un párroco, como su pastor propio" (p. $515,1)$. Autores como Cisoc postulan que es en la parroquia donde la Iglesia se hace actual y visible a los fieles y al mundo.

En materia de concepciones espaciales e improntas territoriales, los edificios religiosos no son solo construcciones materiales y objetivas, sino que son y portan significatividad, imaginación, representaciones, imaginarios, experiencias y utopías. La parroquia es, ante todo, un lugar de encuentro y de desarrollo de un tipo específico de experiencia, que es acogido en los nuevos estudios culturales (Cosgrove, 1988). En estos se aplica y promueve un conjunto de métodos de investigación, de paradigmas desde los cuales observar, describir, analizar y explicar una realidad histórica, témporo-espacialmente irrepetible, en la cual tienen lugar conflictos de poder, procesos de reproducción social, lógicas de dominación y agenciamientos (Lehmann, 2002).

\section{Objetivos e hipótesis}

El objetivo general del estudio fue conocer y analizar las relaciones existentes entre la localización de edificios católicos y las características socioeconómicas de los habitantes del Área Metropolitana de Santiago de Chile (AMS). En forma específica, se fijaron los objetivos de localizar y espacializar los edificios católicos, caracterizar y analizar la población católica por comuna para el período 1992-2002, y conocer los lineamientos de la institución católica sobre la localización de sus edificios.

La hipótesis manejada es que las comunas que cuentan con los niveles socioeconómicos más altos del área de estudio (centro y nororiente de la ciudad de Santiago) son los que concentran el mayor número de parroquias, y la ausencia de estas en las comunas más pobres de la periferia posiblemente ha influido en el descenso del número de creyentes entre los años 1992 y 2002, ello debido a que las parroquias son los lugares donde se vive la fe cristiana y donde se otorgan los sacramentos. 


\section{Marco metodológico}

El primer paso metodológico correspondió a la obtención de la nómina de edificios católicos a escala comunal para el AMS, a partir de la información oficial entregada por el Arzobispado de Santiago, la Diócesis de San Bernardo y la Arquidiócesis de Santiago. Estos edificios fueron espacializados por medio del proceso de geocodificación sobre la trama urbana de Santiago, y las comunas jerarquizadas según el número de parroquias y capillas existentes en cada una.

En segundo lugar, para la caracterización y análisis de la población católica por comuna se identificó el número de fieles a partir de los censos de 1992 y 2002, procediendo con el cálculo de la variación intercensal, lográndose con ello una idea de la dinámica de cambio en cada unidad administrativa descrita en la cartografía temática asociada. Conjuntamente, se revisó el Índice de Desarrollo Socioeconómico (IDS) propuesto por Hidalgo y Borsdorf (2005), estableciendo, para las unidades de análisis, relaciones entre el nivel de vida y el número de católicos en las mismas.

Para visualizar la distribución de fieles católicos en el AMS, el tercer paso fue trabajar con la base de datos microcensales del año 2002 a escala de distrito, y espacializarlos bajo la cobertura de las parroquias. Luego se procedió al cálculo del centro de gravedad de las parroquias, mediante el cómputo de la media aritmética de las coordenadas geográficas de cada punto (Coordenada Norte y Coordenada Este), y se analizó las correspondencias entre este punto de mayor accesibilidad a todos los puntos que integran el sistema y la concentración de creyentes en ciertos distritos censales.

Al mismo tiempo, se estimó la segregación sociorresidencial de los fieles según el Índice de Segregación de Duncan y Duncan (1955), extraído de Martorini y Hoberg (2004), el cual se resume en la siguiente expresión:

$$
\mathrm{IS}=\frac{1}{2} \sum_{\mathrm{i}=1}^{\mathrm{n}}\left|\frac{\mathrm{x}_{\mathrm{i}}}{\mathrm{X}}-\frac{\mathrm{t}_{\mathrm{i}}-\mathrm{x}_{\mathrm{i}}}{\mathrm{T}-\mathrm{X}}\right| \quad 0 \leq \mathrm{IS} \leq 1
$$

donde:

$\mathrm{x}_{\mathrm{i}}$ : Número de habitantes del grupo minoritario en la sección censal i, esto es, fieles católicos en la comuna

$\mathrm{X}$ : Número total de fieles católicos del AMS

$t_{i}$ : Número total de personas en la comuna

T: Número total de personas del AMS

$\mathrm{n}$ : Número de secciones del AMS

El cuarto paso correspondió al cálculo de la variación intercensal de fieles católicos para el período 1992-2002, a partir de los datos entregados por los Censos Nacionales de Población y Vivienda de ambos años.

Como método de apoyo se recurrió a los resultados de la Encuesta de Caracterización Socioeconómica Nacional (Casen) 2006, a cargo del Ministerio de Plani- 
ficación, considerando específicamente los datos de pobreza total en las comunas del AMS. Ello permitió identificar grupos comunales de conducta similar respecto del número de capillas y parroquias disponibles; comportamiento intercensal de los fieles católicos, evangélicos y mormones; y las tasas de número de fieles católicos por parroquia y capilla.

Finalmente, se llevó a cabo una entrevista a dos de los vicarios de la región Metropolitana y al director de Infraestructura de la Pontificia Universidad Católica de Chile, para precisar los lineamientos generales en cuanto a la localización de la infraestructura, además de comparar las visiones que existen en las distintas zonas.

\section{Los fieles católicos en Chile}

Según Lehmann (2001), la observancia religiosa (entendida como el porcentaje que practica su culto una vez a la semana o más frecuentemente) ha disminuido considerablemente en Chile, especialmente en la religión católica. Mientras que en 1958, en el Gran Santiago, el 33 por ciento de los católicos era observante, en 1998 esa cifra había descendido a 18 por ciento. En términos comparativos con otros países del mundo, Chile se ubica en niveles muy parecidos a la media europea y por debajo de los países latinoamericanos.

El censo del año 2002, realizado por el Instituto Nacional de Estadísticas, reveló que la población del país era de 15.151 .076 habitantes, de los cuales 73 por ciento se declaraba católico, 6 por ciento menos que lo registrado en el censo de 1992. En particular, las regiones que más habían disminuido su población católica con respecto de la población total eran Tarapacá, Antofagasta, Aysén y Metropolitana de Santiago, con una disminución en torno al 7 por ciento. En tanto, la región del Biobío poseía el menor porcentaje de población católica del país, con 58 por ciento.

Por otra parte, la Vicaría de Educación informaba en el año 2005 que el número de habitantes en Chile por sacerdote era de 6.422, mientras que el número de católicos por sacerdote era de 3.329. Con relación a los centros pastorales, en el país se contabilizaban 2.990 edificios, de los cuales 931 correspondían a parroquias.

En el Área Metropolitana de Santiago el 68,7 por ciento de la población se consideraba católica, es decir, unos 3.130 .000 de habitantes, para los que se contaba con 352 sacerdotes diocesanos y 507 sacerdotes religiosos, distribuidos en 200 parroquias, 429 capillas y 243 colegios católicos. A nivel comunal se observa que la disminución del número de fieles católicos es generalizada en todas las entidades (Figura 1). Las comunas que tuvieron una tasa de reducción mayor fueron Providencia (-11,10 por ciento), La Reina (-10,00 por ciento) y La Florida (-9,69 por ciento), siendo esta última comuna una de las tres que tienen mayor presencia de católicos, en tanto las comunas que experimentaron una menor reducción de fieles fueron Santiago (-1,15 por ciento), Lo Barnechea (-2,31 por ciento) y Peñaflor $(-2,92$ por ciento). 
FIGURA 1 | Variación intercensal de fieles católicos en el AMS, 1992-2002

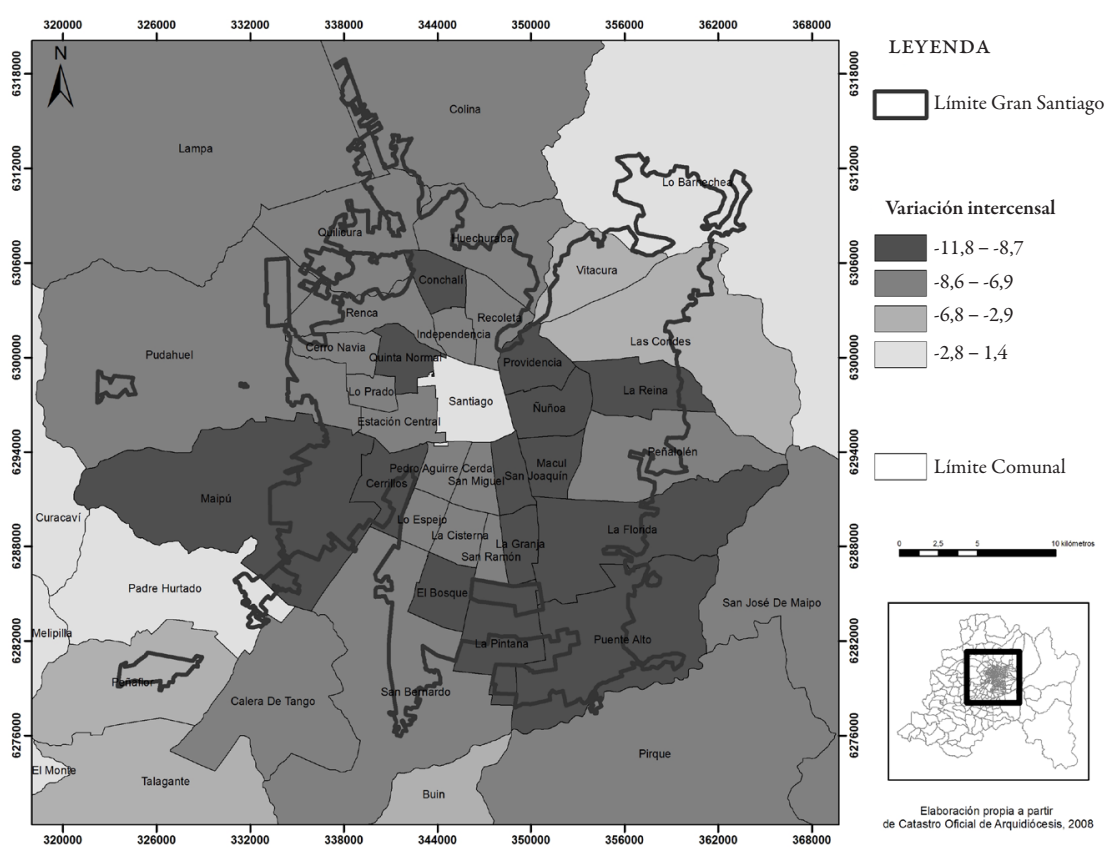

Fuente elaboración propia a partir de Catastro Oficial Arquidiócesis, 2008.

Esta significativa disminución de los católicos, tanto de observantes como de no observantes, podría tener su explicación en diversos procesos ocurridos en las últimas décadas. En primer lugar, se encuentra la participación por estratos sociales de grupos católicos en el sistema educacional nacional. La prelatura del Opus Dei, los Legionarios de Cristo, Schönstatt, jesuitas, entre otros, por medio de la fundación y administración de colegios y universidades destinados a los niveles socioeconómicos medios altos y altos, han favorecido una evangelización permanente, influyendo en la adscripción de las generaciones precedentes y la prevalencia de esta religión al interior del grupo familiar, aun cuando no sean observantes. En contrapartida, los grupos sociales más pobres en un principio no han formado parte de este "público objetivo", con lo cual han tenido menos posibilidades de acceder a instituciones educacionales cercanas al credo católico, con la consecuente pérdida de cercanía con los postulados de la Iglesia. Conscientes de esta omisión, los grupos católicos han comenzado a corregir tal proceso con iniciativas como la Fundación Belén Educa y la Fundación Mano Amiga, que localizan establecimientos educacionales en zonas habitadas por población vulnerable. ${ }^{1}$

1 Véase sitios web, http://www.beleneduca.cl, http://www.manoamiga.cl/fundacionma.html 
Un segundo aspecto se relaciona con la diversidad religiosa. Para el caso chileno, este fenómeno estaría asociado al crecimiento explosivo de las vertientes carismático-pentecostales desde los inicios del siglo XX y la emergencia de distintas transformaciones y sincretismos al interior de las religiones católica y protestantes tradicionales, fenómeno que también se ha dado con similares características en el resto de América Latina y en otros países del globo (Fontaine \& Bayer, 1991). En Chile, estos credos se han fortalecido en los estratos más bajos de la sociedad, que para sus actividades ocupan viviendas, antiguos cines u otros espacios reacomodados para fines litúrgicos, razón por la cual se distribuyen tanto al interior del casco histórico como en la periferia urbana. Destacan también las prácticas de teleevangelismo, la presencia de programas de difusión de la religión evangélica en el dial AM, una radio evangélica en el dial FM, que incrementan la cobertura espacial de estas religiones al interior de la ciudad. Es posible que el aumento en la oferta de religiones haya incidido poderosamente en la disminución de la hegemonía de la Iglesia católica, al presentar un modelo de fe que ha hecho suyas las aspiraciones y expectativas de los sectores más desposeídos y con un menor nivel de instrucción. Reducen la experiencia religiosa a las emociones y a la búsqueda de experiencias místicas diferenciadoras que asumen la función de integración de los individuos a núcleos sociales de afectividad, que reemplazan aquellas otras modalidades de asociación debilitadas por el neoliberalismo y la globalización (Tincq, 1997).

Por último, se encontraría el rezago territorial de la Iglesia católica. Sus modalidades de evangelización influyen en la distribución territorial de las instalaciones, en tanto las vicarías y otras modalidades de administración gestionan recursos preexistentes y sobre ellos sostienen la divulgación de la fe, aun cuando pueda existir la sensación de que la infraestructura no es suficiente y que es necesario ocupar otras áreas de expansión urbana reciente. Probablemente esta práctica puede incidir en el comportamiento espacial de los datos, pero implica administrar adecuadamente el capital simbólico ya instalado y la preferencia que tiene la población para acceder a centros de culto tradicionales por sobre otros más nuevos o recientes, asociada a la devoción de imágenes o símbolos honrados por la tradición. A pesar de que existen templos, parroquias o capillas al interior de colegios católicos instalados en distintas comunas de la ciudad, estos funcionan en días hábiles y tienen restringido su acceso al público en general. Por este motivo, se trata de espacios de culto subutilizados, lo que en algunos casos se agrava por la imposibilidad de contar con ministros que puedan administrar los sacramentos periódicamente, a pesar de existir las condiciones de infraestructura requeridas.

Adicionalmente, aquellos intereses religiosos que han sobrevivido a los procesos de secularización tienen en la actualidad instancias de satisfacción distintas a las propuestas por las religiones tradicionales, lo que afecta especialmente a la fe católica. Tal es el caso de la irrupción de cultos formales e informales, como es el caso de algunas religiones orientales, así como el desarrollo de sectas que ocupan viviendas o edificaciones en donde se comparten usos — sanaciones, venta de productos 
naturistas o salas de charlas o de convenciones - y los lugares de culto dedicados específicamente a las animitas u otros hitos santificados de forma popular. La ventaja de este tipo de sitios se relaciona con el bajo nivel de inversión necesario para desarrollar las prácticas religiosas, al ser muchos de ellos lugares de paso, frágiles y móviles, que fijan una permanencia limitada de las personas en ellos.

A pesar de esta situación de declive, se deben tener en cuenta algunos aspectos clave que ayudan a explicar parte de los vaivenes de los fieles en general y de la Iglesia católica en específico. Respecto de esta última, hay que destacar las transformaciones de sus dinámicas en materia de evangelización, sobre todo a partir de las disposiciones establecidas por la Encíclica Rerum Novarum y aquellas derivadas del Concilio Vaticano II. En lo concerniente a la Encíclica, la localización de los templos y/o edificaciones religiosas en alguna medida da cuenta de los objetivos que cada congregación persigue en materia de evangelización. Cada grupo religioso orienta su oferta a la captación de posibles interesados al interior de la ciudad. Para el caso chileno (y probablemente para el resto de Latinoamérica), originalmente, la Iglesia católica apostólica romana asoció la detección de esos potenciales fieles a la participación que le cupo en la empresa de conquista, razón por la cual concentró sus edificaciones en el casco histórico de la ciudad y, ya en el siglo XIX, proyectó su presencia a los espacios ocupados por la clase dirigente. Esta tendencia se habría visto modificada desde los albores del siglo XX, a partir de la difusión de la Encíclica Rerum Novarum, en 1891, la cual tuvo gran incidencia en la conformación de lo que posteriormente se conocerá como Doctrina Social de la Iglesia. Dicha Encíclica sostiene en sus inicios que

\begin{abstract}
El ardiente afán de novedades que hace ya tiempo agita a los pueblos, necesariamente tenía que pasar del orden político al de la economía social, tan unido a aquél. La verdad es que las nuevas tendencias de las artes y los nuevos métodos de las industrias; el cambio de las relaciones entre patronos y obreros; la acumulación de las riquezas en pocas manos, y la pobreza ampliamente extendida; la mayor conciencia de su valer en los obreros, y su mutua unión más íntima; todo ello, junto con la progresiva corrupción de costumbres han hecho estallar la guerra. Cuán suma gravedad entrañe esa guerra, se colige de la viva expectación que tiene suspensos los ánimos, y de cómo ocupa los ingenios de los doctos, las reuniones de los sabios, las asambleas populares, el juicio de los legisladores, los consejos de los príncipes; de tal manera, que no hay cuestión alguna, por grande que sea, que más que ésta preocupe los ánimos de los hombres (León XIII, 1891).
\end{abstract}

Todo este escenario de preocupaciones y cambios impulsó a la Iglesia católica a asumir una posición respecto de la cuestión obrera: "Por esto, pensando sólo en el bien de la Iglesia y en el bienestar común, así como otras veces os hemos escrito sobre el Poder político, la Libertad humana, la Constitución cristiana de los Estados y otros temas semejantes, cuanto parecía a propósito para refutar las opiniones engañosas, así ahora y por las mismas razones creemos deber escribiros algo sobre la cuestión obrera" (León XIII, 1891). 
La preocupación se transformó en acción; la Iglesia se orientó hacia el naciente proletariado, al que era necesario adoctrinar localizando templos e instituciones asociadas (tales como hospicios, hospitales, escuelas, entre otros) en las periferias de la ciudad. Es más, en Santiago, las sociedades de beneficencia católicas fueron clave en el inicio de la política de vivienda en Chile y en la promulgación de la Ley de Habitaciones Obreras de 1906. Al mismo tiempo, esas sociedades edificaron los primeros conjuntos de vivienda social que sirvieron de base para la posterior acción del Estado (Hidalgo, 2005).

Hacia mitades del siglo XX (antes del Concilio Vaticano II), las sociedades occidentales, especialmente en el Primer Mundo, avanzaron aceleradamente hacia la secularización, con variados efectos en las iglesias tradicionales. Una facción de los credos católico y protestante reaccionaron abrazando posturas conservadoras, y otras evolucionaron hacia la aceptación de la modernidad, tendencia que, para el caso de la Iglesia católica, se expresaría en algunas de las directrices adoptadas en el Concilio Vaticano II (1962 a 1965). Este correspondió a un encuentro ecuménico en el cual se reflexionó acerca del papel de la Iglesia respecto de los cambios políticos y sociales que se vivieron en esos años, tal como lo señaló el papa Juan XXIII en su discurso inaugural de 1962: "En el presente momento histórico, la Providencia nos está llevando a un nuevo orden de relaciones humanas que, por obra misma de los hombres pero más aún por encima de sus mismas intenciones, se encaminan al cumplimiento de planes superiores e inesperados; pues todo, aun las humanas adversidades, aquélla lo dispone para mayor bien de la Iglesia”.

En los años sesenta (período pos Concilio Vaticano II) y setenta proliferaron, especialmente en Estados Unidos, y también en otros países como Francia y Bélgica, nuevos movimientos religiosos, entre los cuales destacan algunos que habían tenido una existencia soterrada, otros de corte espiritualista, en la línea oriental y de pararreligiones (Champion, 1997). La Iglesia católica, en tanto, acompañó a los nuevos habitantes urbanos provenientes de la migración campo-ciudad que se localizaron en las periferias, como también a los obreros que nacían de los ensayos de la industrialización puestos en marcha bajo la lógica del Estado de Bienestar de corte fordista. Con cierto retraso, tanto en América Latina como en Chile se pudieron apreciar los efectos de la secularización, que influyeron en la generación de nuevas formas de comprender el hecho religioso, sin que ello implicara el abandono de este factor como ordenador de la vida de individuos y colectividades (Galilea, 1987; Gaete, 1986; Salas, 1967; Fontaine \& Bayer, 1991; Lehman \& Hinzpeter, 1999; Lehman, 2002).

Entre la década de los setenta y parte de los ochenta, período en el cual se aplicaron en diversos países del Tercer Mundo economías neoliberales abiertas en el marco de dictaduras, surgieron integrismos y fundamentalismos tanto en esos países como en algunos del Primer Mundo. Al mismo tiempo, proliferaron creencias de carácter individualista, amoldadas al gusto e interés de los feligreses y con una teología flexible y relativa, especialmente en Estados Unidos, Europa y Latinoamérica (Champion, 1997). 
En los ochenta y noventa destaca la tendencia a la búsqueda de la felicidad individual mediante lo espiritual (Champion, 1997, p. 538). Con relación al mundo católico, desde los ochenta en adelante se aprecia una brusca disminución en la adherencia y en la observancia, tendencia que se repite, aun cuando a escalas menos significativas, en las religiones de denominación protestante. Surge una generación de feligreses que practican una "religión a la carta" y que combinan sus creencias tradicionales con enfoques de origen humanista, oriental, místico oriental, esotérico o de otra índole (Lehmann, 2002; Gökariksel, 2009a; Holloway, 2006; Pontificia Universidad Católica de Chile [PUC]-Adimark, 2008; Fontaine \& Bayer, 1991; Gaete, 1986; Galilea, 1987; Santos, 2008; Lehman \& Hinzpeter, 1999), que se manifiestan con tiendas de venta de productos afines al culto, lugares de formación en yoga, reiki y otras disciplinas, centros de veneración y culto, entre otros.

Aun considerando estas diferentes situaciones acaecidas a lo largo del siglo XX, y a pesar del relativo declive de la fe católica, ella sigue siendo hegemónica en Chile y presenta algunas constantes, como su destacado rol asistencialista en materia de ayuda social y auxilio político, y una fuerte presencia en la cultura popular mediante ritos, prácticas y símbolos, los cuales incluso alcanzan a aquellos que practican credos diferentes. ${ }^{2}$ Lo anterior ha permitido a la Iglesia católica presentar una pátina exitosa en materia de la enculturación de valores y creencias, asociada al prestigio que manifiesta transversalmente en toda la sociedad.

\section{Características de la distribución de infraestructura católica en el Área Metro- politana de Santiago}

A partir de las nóminas de edificios católicos en el AMS, puede identificarse un patrón de distribución heterogéneo en el área de estudio. Por un lado, la concentración total disminuye a medida que aumenta la distancia al centro (Figura 2); y por otro, varía el tipo de edificación católica por vicaría: en la Vicaría Centro y la Vicaría Cordillera las parroquias tienen carácter exclusivo, mientras que en las otras vicarías las parroquias se ven acompañadas de capillas y Comunidades Eclesiales de Base (CEB). ${ }^{3}$

Es así como la comuna de Santiago tiene la primacía respecto de la presencia de parroquias en el área de análisis, con un total de 29 edificios. Más atrás se encuentran las comunas de San Bernardo (13 parroquias), Providencia (11 parroquias), y Las Condes y Nuñoa con 10 unidades. Respecto de las capillas, Maipú y Cerro Navia son las comunas que cuentan con el mayor número de ellas, con 26 y 23 de estos edificios, respectivamente.

Si bien este patrón de distribución permitiría inferir que la disposición de las parroquias obedece a la forma de consolidación de la ciudad de Santiago, se deben

2 Un ejemplo de lo anterior puede apreciarse en la información proporcionada por la Encuesta Bicentenario, que muestra claramente la devoción mariana de los chilenos, la creencia en el cielo y en el infierno y la devoción a los santos, que incluso alcanza a aquellos que se declaran evangélicos en los estratos sociales más bajos (PUC-Adimark, 2008).

3 En Chile corresponden a un "grupo de creyentes, generalmente asociados a una parroquia, que viven su compromiso con Jesucristo, juntos, de manera estable y fraternal. Se reúnen periódicamente a estudiar, orar, programar acciones apostólicas" (Conferencia Episcopal de Chile, 2008). 
agregar otros aspectos relacionados con las características de la población católica. De esta forma se obtendrá una mejor comprensión de la distribución de la infraestructura católica y su contribución al dibujo del territorio metropolitano.

FIGURA 2 | Localización de edificaciones católicas en el AMS según Vicarías

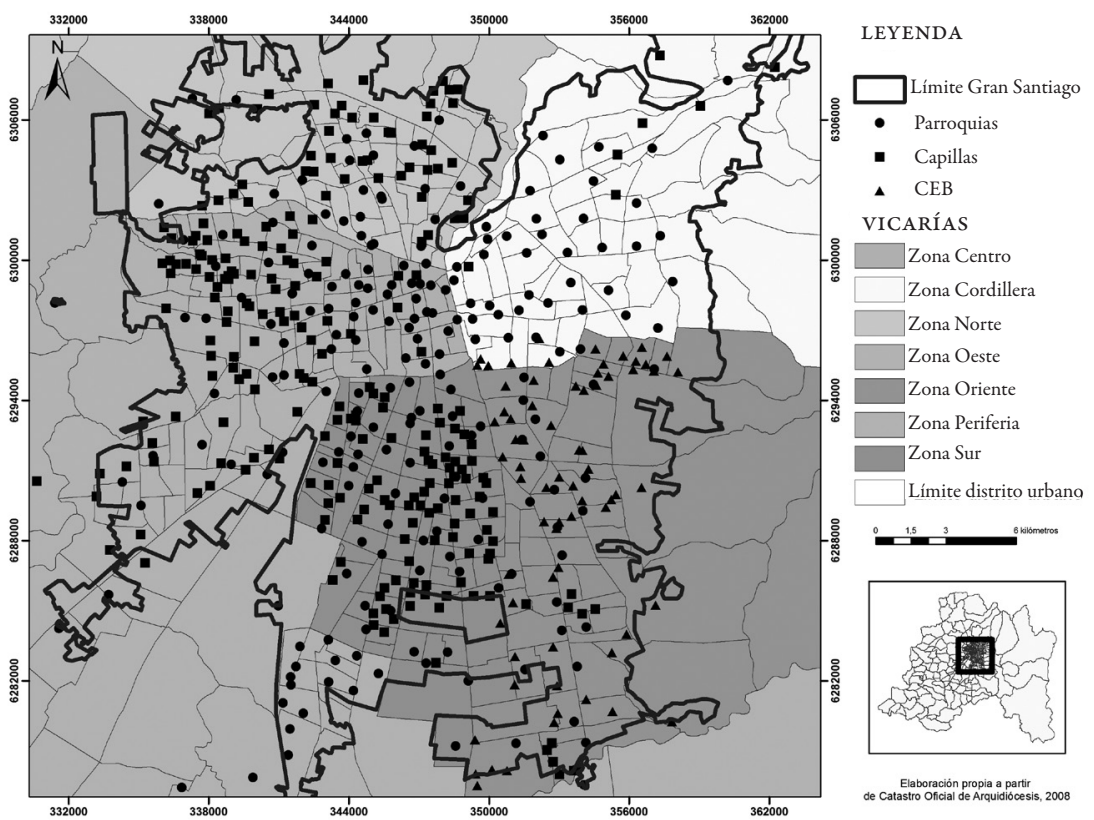

fuente Elaboración propia a partir de Catastro Oficial Arquidiócesis, 2008.

\section{La distribución según el número de fieles católicos}

En una distribución óptima, el centro de gravedad de las parroquias debiera coincidir con el distrito que tenga mayor cantidad de fieles dentro de la comuna. Sin embargo, la Figura 3 muestra que el patrón distributivo de parroquias católicas no concuerda con la distribución de los fieles. Mientras que la Vicaría Centro es la que tiene mayor número de lugares de culto católico, concentra porcentajes de población católica menores que otras comunas del área norte y sur. El centro histórico se ha visto inundado de edificios de actividad comercial, y el uso residencial se ha destinado, básicamente, a acoger hogares unipersonales, lo que ha repercutido en la cantidad de fieles que profesan hoy la fe católica en el centro de la ciudad. 
FIGURA 3 | Número de católicos por distrito y las edificaciones católicas en el AMS

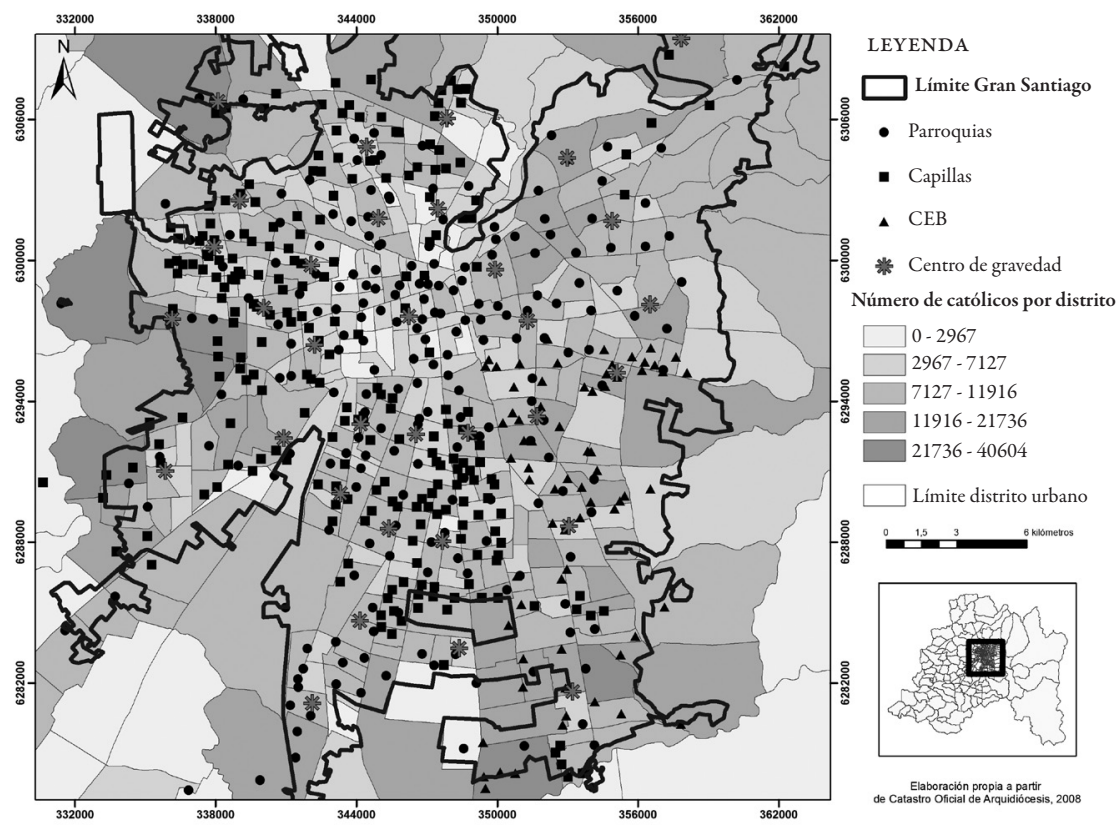

FUente elaboración propia a partir de Catastro Oficial Arquidiócesis, 2008.

Situación diametralmente opuesta ocurre en los distritos periféricos del AMS, pues si bien son estos los que más han incrementado su población en el último periodo intercensal y, por ende, tienen un mayor número de fieles católicos, presentan una menor cantidad de parroquias. En la práctica, solo coinciden los centros de gravedad con los distritos más populosos en las comunas de Vitacura, Lo Barnechea, Quilicura y Pudahuel, mientras que ambos elementos no se corresponden en Santiago, Recoleta, Quinta Normal, Maipú, Cerrillos, Las Condes, Peñalolén, La Florida y Huechuraba. En las comunas restantes la situación es relativa, pues el centro de gravedad se instala en puntos limítrofes entre distritos con distinta concentración de creyentes.

\section{La distribución según la segregación sociorresidencial de los fieles católicos}

La segregación residencial en una ciudad indica el nivel de desigualdad de la distribución de la población entre las diferentes zonas (Martorini \& Hoberg, 2004). La segregación socioespacial, fenómeno característico de la urbanización (Cabrales, 2002), se define como la tendencia a organizar el espacio en zonas con sólida 
homogeneidad social interna y fuerte disparidad social entre ellas; esta última está comprendida no solamente en términos de diferencia, sino de jerarquía. La producción de la ciudad segregada puede crear núcleos definidos en el territorio, pero estos no tienen una relación directa con el tejido urbano que los rodea (Castells, 1975). Más específicamente, comprende el grado de proximidad espacial o de aglomeración territorial de las familias pertenecientes a un mismo grupo social, sea que este se defina en términos étnicos, etarios, de preferencias religiosas o socioeconómicos, entre otras posibilidades (Sabatini, Cáceres \& Cerda, 2001); en este caso particular se estudió la población de fieles católicos versus el resto de la población.

En la Figura 4, que clasifica las comunas del AMS según el índice de segregación, se observa que los católicos tienen una distribución más o menos homogénea en el área analizada, pues de un mínimo de cero (0) y un máximo de uno (1), los valores de segregación en el área metropolitana van entre 0,01 y 0,85 , lo que quiere decir que, en promedio, la población que tiene una desigual distribución en el espacio físico es menor al 1 por ciento por comuna. Esto se debe a la primacía de católicos en todas las unidades territoriales administrativas comunales estudiadas.

FIGURA 4 | Índice de segregación espacial para el año 2002 en el AMS

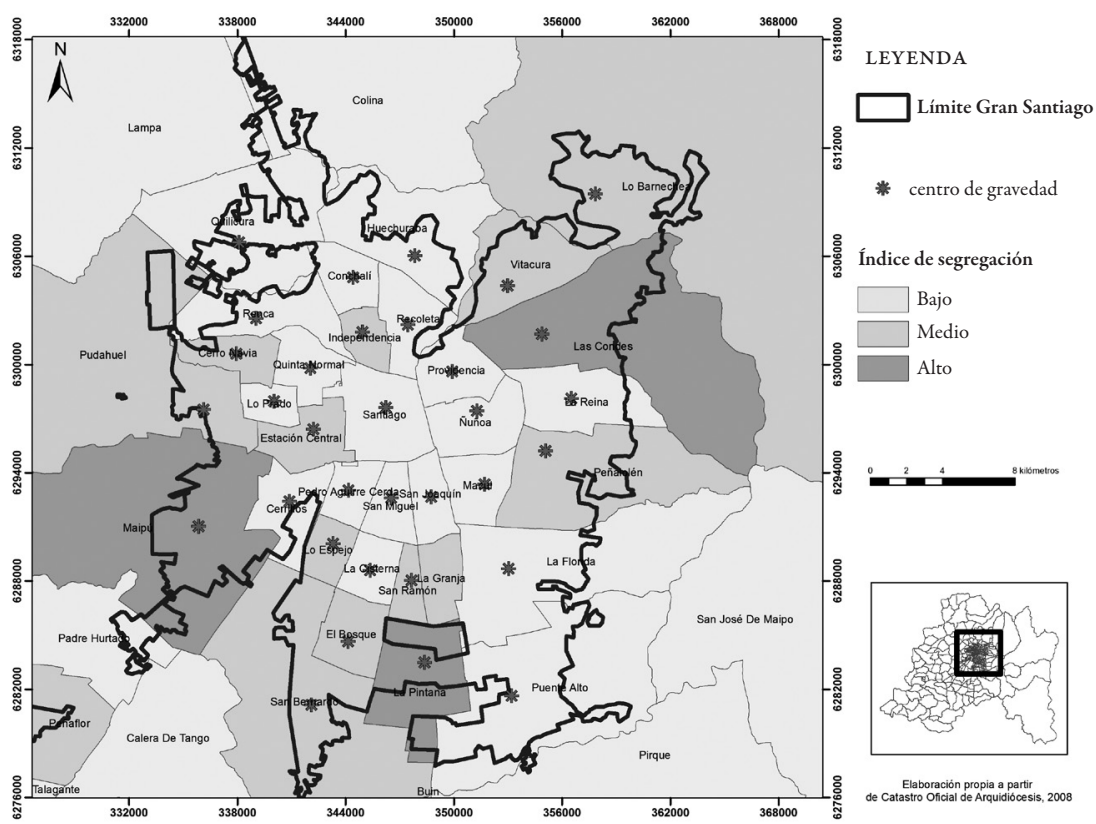

FUente elaboración propia a partir de Catastro Oficial Arquidiócesis, 2008. 
La instalación de la Iglesia católica en la ciudad de Santiago tuvo un carácter hegemónico hasta bien entrado el siglo XX. Por esta razón, la localización de los templos es homogénea en el casco fundacional de la ciudad. A partir de la primera década del siglo XX, las Iglesias evangélicas tradicionales y aquellas carismáticas surgidas desde 1906 se instalaron en barrios obreros emergentes, especialmente en el sector poniente de la ciudad. Solo en épocas recientes estos credos se han localizado en las proximidades del casco histórico en antiguos cines, talleres, galpones o pisos completos de algunos edificios. Esta tendencia modifica, en alguna medida, la hegemonía de la Iglesia católica en el centro de la ciudad.

Los índices más altos de segregación se encuentran en las comunas de Las Condes y La Pintana. En la primera alcanza el valor 0,85, lo que se traduce en que el 0,85 por ciento de la población católica que vive en la comuna debería localizarse en otro lugar para que la distribución de los fieles fuera homogénea a nivel metropolitano. Lo mismo ocurre en La Pintana, que cuenta con un índice de 0,74 , lo que equivale a que el 0,74 por ciento de los fieles debería mudarse a otro lugar del área metropolitana para equiparar la distribución de fieles.

En el otro extremo se encuentran las comunas que tienen menor concentración de católicos. Los valores más bajos se dan en las comunas de Cerrillos $(0,01)$ y San Bernardo $(0,02)$, las que necesitarían recibir más población católica para definir una situación homogénea de fieles en el AMS.

Cabe destacar que las comunas que se encuentran en la periferia del Área Metropolitana muestran niveles de segregación inferiores en comparación con las comunas centrales y caracterizadas como urbanas, de lo que podría inferirse que existe un gradiente centro-periferia en la segregación en el AMS. Sin embargo, esto no implica que en las zonas rurales existan menos fieles católicos, ya que, en términos comparativos, las zonas rurales son las que mantienen niveles de variación intercensal más bajos.

\section{La distribución según el desarrollo socioeconómico de la población}

Desde mediados de los años ochenta del siglo pasado, Chile comenzó a experimentar grandes transformaciones económicas, que dieron paso a un nuevo panorama en materia de las condiciones de vida de la población. Sin embargo, este crecimiento no ha sido homogéneo en el territorio, tal como muestra el Índice de Desarrollo Socioeconómico (IDS) para la población del Área Metropolitana de Santiago.

En el año 1992 (Figura 5), las comunas que tenían un mayor valor en el IDS $(1,94-2,82)$ correspondían a aquellas localizadas en el llamado cono de altos ingresos (Lo Barnechea, Las Condes, Providencia, La Reina y Vitacura). En los distritos centrales de la ciudad de Santiago, los valores se presentan de una forma heterogénea: los distritos presentan valores que varían de medio a bajo (entre 0 y 1,93 puntos de un máximo de 3). El centro-poniente del área metropolitana presenta una fragmentación de los niveles de calidad de vida, mientras las comunas de la periferia sur y norte son las que tienen los valores más bajos. 
FIGURA 5 | Índice de Desarrollo Socioeconómico para el año 1992, región Metropolitana

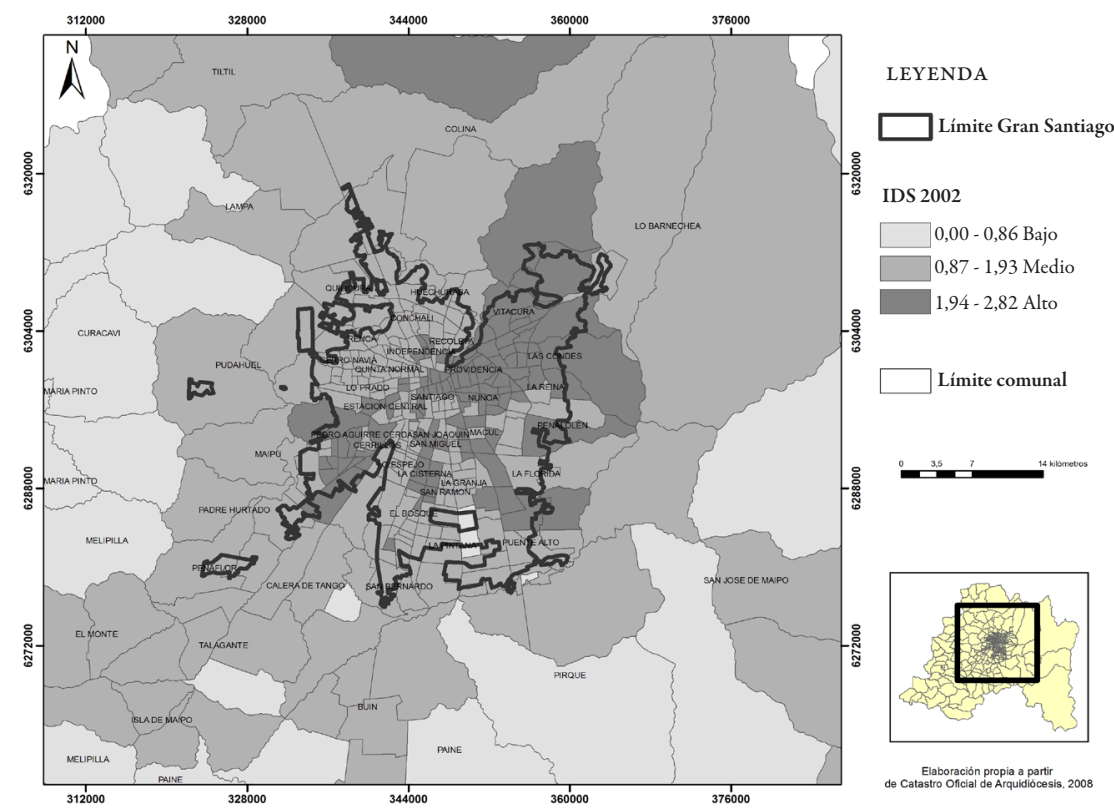

FUente elaboración propia a partir de Catastro Oficial Arquidiócesis, 2008.

Diez años después (Figura 6), si bien se distingue una evolución positiva de la calidad de vida, la hegemonía de la denominada cuña de altos ingresos se mantiene, al presentar los mayores niveles de vida (entre 1,96 y 2,7 puntos de un máximo de 3), aunque ahora se aprecian pequeños puntos aislados, como San Miguel, que comparten esa tendencia. El nivel de vida más bajo se sigue concentrando en los distritos de las comunas de las periferias sur y norte.

Un aspecto de la calidad de vida de la población tiene que ver con el rol de las agrupaciones religiosas en materias como la cohesión social, identidad, sentido de pertenencia y pérdida del anonimato. Las religiones carismáticas, por ejemplo, contemplan como modalidades de fidelización la integración de los individuos a un grupo que los acoge y valora, opción que aporta a su difusión. Por lo general emplazan sus establecimientos en la cercanía de los hogares de los feligreses y, en la medida en que crece la membrecía, instituyen misiones que tienen por objetivo evangelizar en otros sectores de la ciudad, generalmente del mismo estrato socioeconómico del lugar desde el cual comienza la expansión. El credo católico, en cambio, manifiesta fortalezas en procesos asociados a la homogeneización social, ya que los feligreses participan de cultos entre iguales y solo ocasionalmente establecen relaciones personales más profundas mediante organizaciones asociadas al culto, tales como la catequesis, las instancias de beneficencia y voluntariado, entre otras. 
FIGURA 6 | Localización de edificaciones católicas e Índice de Desarrollo Socioeconómico en el AMS

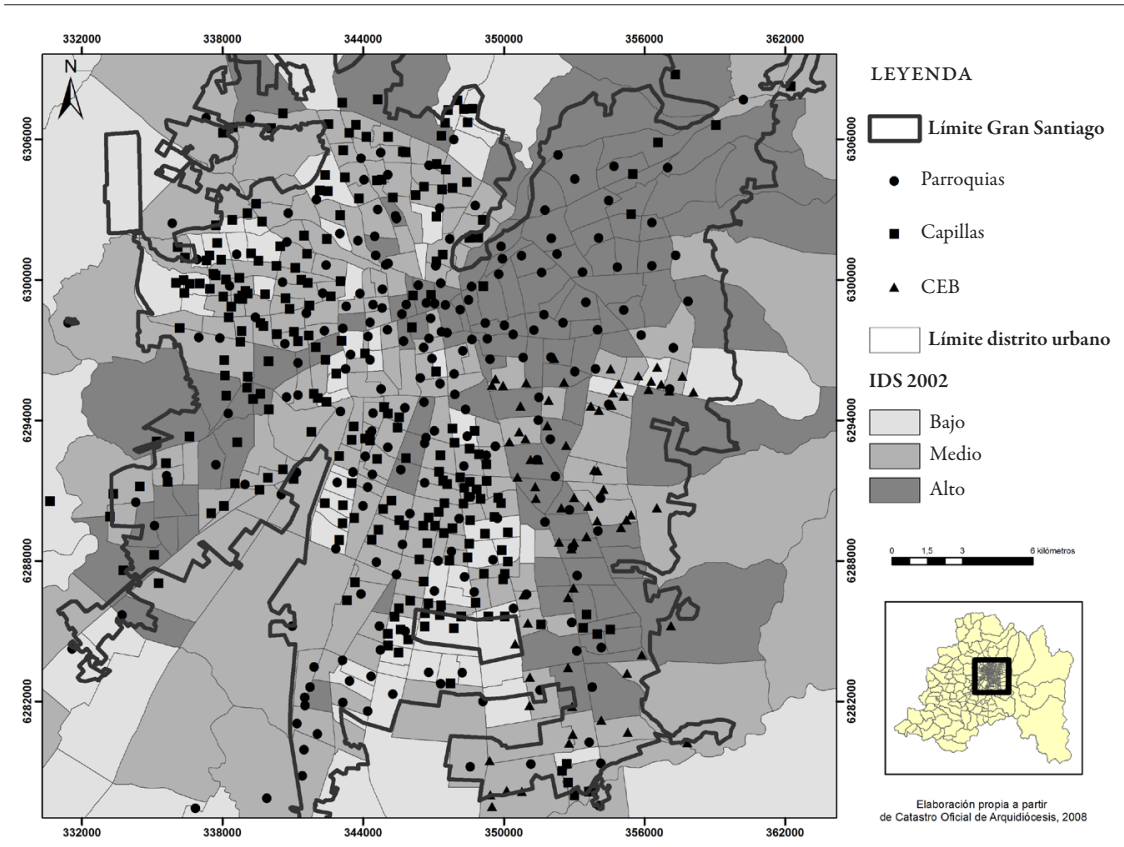

FUente Elaboración propia a partir de Catastro Oficial Arquidiócesis, 2008.

Si se relacionan estas características socioeconómicas de la población con la distribución de edificios católicos (Figura 6), se observa que las capillas se distribuyen en las zonas que cuentan con población de menor nivel socioeconómico, mientras que las parroquias, si bien están presentes en toda el AMS, tienen mayor concentración en la Vicaría Centro y la Vicaría Oriente. Podría pensarse que la distribución de edificios católicos se encuentra asociada al nivel socioeconómico de la población de forma directa, ya sea por el orden de consolidación de áreas urbanas, o por la tradición católica de los grupos más acomodados, que datan del catolicismo tradicional conservador. Los grupos de mayores ingresos pueden aportar monetariamente a la mejora o a la construcción de edificios de culto, lo que influye en la mayor cobertura que se presencia en las figuras presentadas.

\section{La distribución según los niveles de pobreza de la población}

Maipú, Puente Alto, La Florida y Las Condes son las comunas que tienen mayor número de fieles católicos en el AMS, según el Censo del año 2002, superando todas los 150.000 fieles. Las tres primeras comunas corresponden a las más populosas a escala regional. En términos relativos, la tasa de habitantes por parroquia obedece a la proporción de fieles que serían potencialmente atendidos por cada templo dentro de la comuna de residencia. Respecto de este cálculo, la comuna de Santiago 
sería la que presenta una mayor cobertura de edificios católicos, de acuerdo con los fieles existentes, con una tasa menor a 5.000 fieles católicos por inmueble.

Considerando ahora la tasa de cobertura de las parroquias y capillas, la atención potencial de los fieles se descomprime un poco, aunque las comunas con mayor déficit de parroquias se mantienen. Los déficit de cobertura de parroquias en los casos de Peñalolén (33.952 fieles/parroquia), Lo Barnechea (20.404 fieles/parroquia) y Las Condes (13.910 fieles/parroquia), si bien son altos, se suplen con la existencia de CEB cercanas, en la Vicaría Oriente. Un factor que influye en la dinámica espacial de la población que accede a los centros de culto es la disposición de un sistema de transporte público o privado que le permita acceder a distancias mayores. Ello inhibe la necesidad de edificar centros en las cercanías de la residencia, situación que explicaría cierto rezago en la instalación de iglesias en comunas de ingresos medios, medios altos y altos. Por otra parte, las capillas y parroquias se asocian a determinadas órdenes, prelaturas, o a determinados santos o imágenes de culto, lo que genera cierto margen de inmovilidad en materia de la devoción popular.

Si se asocian estos resultados con el nivel de pobreza en cada comuna (Cuadros 1 y 2), se advierte que en las comunas que tienen entre 10 y 15 por ciento de pobres, las personas tienen menos parroquias donde asistir (21.167 fieles/parroquia). En cambio, en las comunas que presentan menos porcentajes de pobreza, cada persona debiera compartir la parroquia con alrededor de 10.000 fieles menos, potenciando la oportunidad de atención por parte de la comunidad eclesiástica (párroco). Pese a esta dificultad, en los casos de pobreza crítica el nivel de cobertura de las parroquias es mejor que en el de las comunas con menor pobreza, con 14.000 fieles por parroquia, frente a casi 20.000 fieles por parroquia. Las capillas amplían la cobertura y mejoran la situación en todos los niveles comunales, sobre todo en el porcentaje de comunas menos aquejadas por la pobreza (3.600 fieles por parroquia y/o capilla). Desde ese rango, la cobertura comienza a disminuir de forma constante hasta llegar a 8.400 fieles por parroquia y/o capilla en comunas con pobreza superior a un 15 por ciento.

CUADRO 1 | Nivel de pobreza por comuna del AMS

\begin{tabular}{l|l}
\hline COMUnas & $\begin{array}{l}\text { NIVel DE POBREZA } \\
\text { TOTAL }\end{array}$ \\
\hline $\begin{array}{l}\text { Las Condes, San Miguel, Providencia, Nuñoa, Vitacura } \\
\text { Cerrillos, Calera de Tango, Independencia, Pedro Aguirre Cerda, Quilicura, Pudahuel, } \\
\text { Santiago, Estación Central, San Joaquín, La Reina, Conchalí, Lo Barnechea, Talagante, } \\
\text { Peñaflor, La Cisterna, Peñalolén, Maipú, Pirque, Isla de Maipo, Tiltil, La Florida }\end{array}$ & entre 2 y 5\% \\
$\begin{array}{l}\text { Puente Alto, Quinta Normal, San José de Maipo, Lo Prado, Recoleta, Colina, Buin, Paine, } 10 \% \\
\text { Macul, La Granja, Huechuraba }\end{array}$ & entre 10 y $15 \%$ \\
$\begin{array}{l}\text { El Bosque, San Ramón, La Pintana, Cerro Navia, Lampa, Padre Hurtado, Renca, Lo Espejo, } \\
\text { San Bernardo, El Monte }\end{array}$ & más del 15\% \\
\hline
\end{tabular}

FUENTE ELABORACIÓN PROPIA. 
CUADRO 2 | Cantidad de fieles por parroquias y capillas en el AMS, según nivel de pobreza

\begin{tabular}{|c|c|c|}
\hline $\begin{array}{l}\text { NIVEL DE POBREZA TOTAL } \\
\text { COMUNAL }\end{array}$ & FIELES CATÓLICOS/PARROQUIAS & $\begin{array}{l}\text { FIELES CATÓLICOS/PARROQUIAS + } \\
\text { CAPILLAS }\end{array}$ \\
\hline entre 2 y $5 \%$ & $19.888,38$ & $3.693,11$ \\
\hline entre 5 y $10 \%$ & $11.848,58$ & $5.165,97$ \\
\hline entre 10 y $15 \%$ & $21.167,77$ & $8.415,95$ \\
\hline más del 15\% & $14.837,06$ & $8.432,56$ \\
\hline
\end{tabular}

FUENTE ELABORACIÓN PROPIA.

Otro aspecto similar se muestra en el Cuadro 3, donde se disponen los promedios de población católica, evangélica y mormona, diferenciados según el nivel de pobreza total comunal. La presencia de fieles católicos está relacionada de forma inversa con el nivel de pobreza de las comunas. A mayor pobreza, menor porcentaje de fieles, disminuyendo la tasa promedio desde el 73 por ciento en comunas que tienen menos de un 5 por ciento de pobres, hasta 65 por ciento en las comunas donde más del 15 por ciento de la población se ve afectada por la pobreza.

CUADRO 3 | Rangos de pobreza y promedios de población católica, evangélica y mormona en el AMS (2002)

\begin{tabular}{l|l|l|l|c}
\hline $\begin{array}{l}\text { NIVEL DE } \\
\text { POBREZA } \\
\text { TOTAL } \\
\text { COMUNAL }\end{array}$ & $\begin{array}{l}\text { \% PROMEDIO } \\
\text { DE POBLACIÓN } \\
\text { CATÓLICA }\end{array}$ & $\begin{array}{l}\text { \% PROMEDIO } \\
\text { DE POBLACIÓN } \\
\text { EVANGÉLICA }\end{array}$ & $\begin{array}{l}\text { \% PROMEDIO } \\
\text { DE POBLACIÓN } \\
\text { MORMONA }\end{array}$ & $\begin{array}{l}\text { \% PROMEDIO OTRA } \\
\text { RELIGIÓN/ ATEOS }\end{array}$ \\
\hline entre 2 y $5 \%$ & 73,0 & 5,3 & 0,5 & 21,3 \\
entre 5y 10\% & 71,2 & 11,9 & 0,9 & 16,1 \\
entre 10 y 15\% & 70,4 & 13,4 & 0,8 & 15,4 \\
más del 15\% & 65,4 & 18,8 & 1,0 & 14,8 \\
\hline
\end{tabular}

FUENTE ELABORACIÓN PROPIA.

El comportamiento observado en los católicos es distinto del que se distingue en la población declarada evangélica. Como se observa en el Cuadro 3, el número de fieles evangélicos es mayor en las comunas más pobres, incrementándose su número de forma continua a medida que la pobreza también aumenta. En la religión mormona la conducta de los fieles es similar a la de los evangélicos, aunque no alcanza a cautivar a más del 1 por ciento de la población.

Finalmente, la asociación de los datos con los niveles de pobreza entregados por la encuesta Casen define la baja en el número de creyentes según el estrato económico comunal. Las comunas con mayor porcentaje de pobreza (más del 15 por 
ciento) perdieron 8,3 por ciento de sus fieles católicos en promedio. Las comunas más pobres fueron las que tuvieron una mayor reducción de practicantes. Una baja similar, no obstante, se vive en las comunas que tienen una situación más favorable, estrechando en 8,1 por ciento el número de seguidores católicos. Las comunas de nivel medio son las que enfrentan menores reducciones, aunque no son muy distantes de los valores de las comunas más pobres y las menos pobres, con 7,2 y 7,9 por ciento, respectivamente.

Conviene detenerse en una reflexión en esta materia. Las religiones evangélicas, especialmente las carismáticas, imprimen en sus devotos una ética que prohíbe el consumo de bebidas alcohólicas, tabaco y prácticas lúdicas, como participación en fiestas. Estas prohibiciones influyen positivamente en la solución a problemas familiares y generan una mejora (en algunos casos muy significativa) en los ingresos con los cuales las familias satisfacen sus necesidades. Por ende, el efecto del credo es inmediato y visible en el corto plazo, tanto en calidad como en el nivel de vida, lo que redunda en su difusión. Asociado a lo anterior, estos credos prometen apoyo y solución a los problemas de salud, lo que es atractivo para determinados estratos de la población que acceden a un servicio de salud de muy baja calidad. Esto aportaría a la explicación de las cifras aquí mencionadas.

\section{La visión de la Iglesia católica}

Con el fin de establecer la existencia de directrices de la Iglesia católica, a la hora de localizar edificios de culto católico en la ciudad de Santiago se realizaron tres entrevistas orientadas principalmente a conocer la relación entre la localización de las parroquias y la caracterización de la población emplazada en las vicarías. A continuación se señalan algunos de los elementos más destacados obtenidos de las mencionadas entrevistas:

- Los lineamientos de la Iglesia católica en la localización de parroquias y templos. Existen dos metodologías de decisión en la construcción de una capilla o una parroquia: a medida que una zona urbana se consolida, la Iglesia adquiere terrenos privados, por donaciones o compra; o al momento de construcción, las comunidades se contactan con las entidades constructoras para edificar un templo de oración. No se trata de un conjunto de normas que se apliquen siempre de la misma forma, sino más bien de pautas que no implican rigidez en su cumplimiento. En sentido estricto, no hay planificación desde una óptica tradicional, sino que se sigue una lógica más bien coyuntural.

- El patrón de localización de las parroquias y capillas. Existe acuerdo en que cada población consolidada cuente con su propio lugar de culto, ya sea una parroquia, cuando la población es menor, o una capilla, cuando la población sobrepasa cierto número de habitantes. Jerárquicamente, una vicaría se divide en parroquias, que en este caso corresponden a una unidad territorial; y dentro de cada parroquia existe un templo central (que comúnmente es llamado 
parroquia), circundado por una serie de capillas de acuerdo con la posibilidad de construcción de la zona en particular. En términos prácticos, la localización de las parroquias y capillas es decidida por el obispo, tras un análisis de los factores económicos y sociales pertinentes.

- La caracterización de los fieles dentro de las vicarias. Cada vicaría lleva el registro del número de fieles y de las actividades realizadas. Si bien las actividades son constantes, se echa de menos la vida de barrio en las zonas de consolidación reciente. Se ve un mayor compromiso en vicarías que abarcan las partes más antiguas de la ciudad, como las de las zonas centro y oriente o el casco histórico de Nuñoa. En palabras del vicario del sector oriente: "Comparado con lugares de mayor nivel socioeconómico, nuestros fieles tienen familias menos estables y menor disponibilidad de estudiar en colegios católicos", lo que incidiría en menores niveles de socialización o en alternativas capaces de reemplazar la vida de barrio anteriormente aludida.

- Demanda por templos de oración. La demanda por lugares de culto es mayor en lugares de consolidación reciente en la región Metropolitana. Las zonas centro y nororiente tienen lugares de culto suficientes; en las zonas norte y periférica se requiere incrementar el número de parroquias y capillas a medida que aumenta la población. Por otra parte, en los últimos años la Iglesia se ha enfrentado a otra problemática, como es la escasez de clero. Se necesitan, entonces, más lugares de culto y personal eclesiástico que dedique su vida a la atención de las parroquias.

- Efectos de la ausencia de parroquias. Según los vicarios entrevistados, existe un conjunto de factores que han determinado la baja en el número de católicos en el período 1992-2002; uno de ellos podría ser la falta de lugares de culto donde vivir la fe. El proceso de secularización de la ciudad tiene que ver con la falta de clero, y también con otros temas culturales, como la falta de tiempo para el descanso o el ritmo acelerado de la vida moderna. Una visión parecida se tiene en la Dirección de Infraestructura de la P. Universidad Católica de Chile, donde se considera que el templo como centro de la vida de barrio ha ido perdiendo su importancia, no solo por una falta de religiosidad de la población, sino por falta de compromiso con la vida cívica en general, lo que lleva a un creciente desinterés por espacios comunitarios, entre los que el templo desempeñaba un papel fundamental.

\section{Consideraciones finales}

Dos aspectos pueden aportar a la explicación de la distribución presentada en este trabajo. El primero se refiere a los costos y/o requisitos de instalación de un edificio de culto. Para el caso de los templos evangélicos, algunos centros de culto en los sectores populares se instalan en las residencias de los fieles y las edificaciones se complican en la medida en que los credos logran más adeptos. En cambio, para el caso de las iglesias católicas, los requerimientos y formas de implementación 
tienden a generar espacios exclusivos y con una infraestructura más desarrollada. Por ende, las posibilidades de movilización asociadas a la precariedad con que se instalan iglesias hacen que los evangélicos puedan levantar templos con mayor dinámica, generándose espacios de acción más personales y reducidos, lo que redunda en su mayor proliferación. Estos centros son atendidos por encargados que surgen entre los mismos conversos, sin que se precise para ello de un proceso de formación específico, lo que aumenta la dotación de actores sociales en condición de predicar y levantar iglesias.

Estas diferencias en los modos de formalizar la construcción de los lugares de culto explican en alguna medida el cierto rezago del mundo católico con respecto del evangélico. La corriente evangélica mayoritaria en Chile, surgida en Valparaíso en 1906, es la Iglesia metodista pentecostal, la cual corresponde a una corriente carismática que se separó del credo metodista wesleyano tradicional. Desde el momento mismo de la escisión, los particulares pertenecientes a ella pudieron "levantar obra” en diversos sectores de las ciudades del país y sus áreas rurales, lo que explica la rápida difusión de esa fe durante la primera mitad del siglo XX, a pesar de la homogeneidad y poder del dogma católico, que se separó oficialmente del Estado solo en 1924. No nacía un lugar de culto cuando ya se estaba pensando en conquistar otros territorios mediante el concurso de un feligrés mediana o casi insuficientemente capacitado para tales fines. En una primera etapa, los templos metodistas pentecostales se instalaron en los sectores proletarios y obreros de las grandes urbes y ciudades intermedias del país. Así como la Iglesia metodista pentecostal es producto de la pujanza de los movimientos carismáticos al interior del metodismo tradicional, otras corrientes carismáticas al interior de la naciente rama se marginaron de los liderazgos recién instalados y se constituyeron en diversas iglesias y/o corrientes pentecostales, que se diferencian de las metodistas pentecostales en la liturgia y en el modo como entienden la evangelización. La profusión de liderazgos influyó en la aceleración de la dinámica de conquista de espacios y de feligreses, siempre concentrados en el proletariado urbano y en los nacientes estratos de obreros industriales de clase media baja y baja que fue generando el modelo de sustitución de importaciones implementado en Chile hasta 1973.

Además, a partir de la década de los ochenta del siglo pasado, comenzó a entrar en crisis en toda América Latina el monopolio de la Iglesia católica; aparecieron nuevos movimientos religiosos que pueden comprenderse como un costo de la opción de este credo por mediar en la solución a los problemas sociales y políticos derivados de los regímenes dictatoriales, del colapso de los modelos de desarrollo y de la irrupción del modelo neoliberal. A ello se suma la emergencia de credos religiosos fundamentalmente evangélicos que se transforman en un nuevo tipo de actor social y luchan por la ocupación de espacios públicos y residenciales asociados a cambios estructurales en la urbanización y en la expansión demográfica. La Iglesia católica vive "un desencuentro entre una lógica cultural y una realidad mutante" (Hourtart, 1997), cuyo primer síntoma de solución será el de una Iglesia asociada a la cultura rural aproximándose al nuevo mundo que emerge de la mano de la 
generación de la clase obrera y de las clases medias (Touraine, 1988). El obrero se transforma en objetivo pastoral del catolicismo, pero los evangélicos llevaban alguna ventaja en ese campo. Ya desde la década de los cincuenta se había acelerado la diversificación de la oferta de mediación entre la sociedad y lo divino, a partir de un modelo de libre mercado en materia de elección religiosa donde las empresas de salvación se multiplican, con la consecuente atomización religiosa (Suárez, 2003).

En el marco del proceso señalado, surge un fenómeno nuevo: la oferta católica parece no adecuarse a los requerimientos de sectores importantes de la población, la que genera en respuesta referentes simbólicos autónomos, adaptados a sus propias necesidades (Suárez, 2003).

Los fenómenos descritos, como todas las manifestaciones sociales, tienen una expresión territorial en las ciudades o fuera de ellas. Santiago, al igual que la mayor parte de las ciudades latinoamericanas, presenta una estructura urbana fragmentada, así como una dinámica territorial donde contrastan en una misma unidad grupos sociales distintos. Esto tiene relación con el auge constructivo de las últimas décadas, especialmente en las áreas periféricas, donde el mercado de viviendas ha aprovechado el bajo valor del suelo para construir muchos proyectos inmobiliarios destinados a viviendas sociales, que son los que han acogido más población en el AMS. Se trata de zonas segregadas tanto espacial como socialmente, marginadas del desarrollo comunal y que acogen a los grupos con mayores dificultades económicas. Su localización, alejada del centro de la ciudad, es desfavorable desde el punto de vista de su conectividad con los demás puntos de la comuna y con los servicios disponibles, incluyendo las parroquias y capillas, que también son un servicio cultural.

En esta perspectiva, las dinámicas territoriales a escala de vicaría — como a escala comunal- establecen ganadores y perdedores; los grupos aventajados desde el punto de vista socioeconómico disfrutan de las mejores localizaciones espaciales respecto de la accesibilidad a templos de culto católico. Lo contrario ocurre con los habitantes de las periferias norte y sur, especialmente. La Iglesia ha seguido la fórmula de edificación de parroquias y capillas en lugares donde le fueron donados terrenos o donde antes el suelo era más barato, lo cual confinó los templos a espacios urbanos ahora consolidados, con bajo nivel de accesibilidad para los grupos socioeconómicos más desfavorecidos que ocupan otros sectores de la urbe.

La hipótesis de que existiría una relación entre la disponibilidad de lugares de culto y el número de creyentes, aunque solo se verifica parcialmente, parece cobrar validez, ya que la ausencia de parroquias en las comunas más pobres de la periferia habría influido en la baja en el número de creyentes en el período 1992-2002, esto debido a que las parroquias son los lugares donde se vive la fe cristiana y donde se otorgan los sacramentos. Sin embargo, si bien las comunas que acogen a las familias más acomodadas concentran el mayor número de parroquias, las comunas pobres son las que presentan el mayor número de capillas, las que, aunque tienen menor jerarquía que la parroquia, cumplen las mismas funciones y mantienen un sacerdote a cargo.

La disposición a financiar la edificación de templos religiosos se asocia a la masa de católicos observantes respecto del total de la población y de la unidad Iglesia y Es- 
tado que caracterizó a Chile hasta 1924. Tanto los agentes privados como el Estado entendían el componente iglesia (edificación) como un requerimiento básico en la estructuración de la ciudad, lo que explica la mayor presencia de templos en el sector tradicional de la ciudad. Por otra parte, la instalación de los estratos sociales bajos en la periferia influye en la menor capacidad económica para levantar templos sin el aporte estatal tras la separación entre el poder político y el religioso. Además, hasta muy entrado el siglo XX, los servicios esenciales para los habitantes de la ciudad eran expedidos desde el centro, con lo cual las iglesias mantienen hasta la fecha un efecto rezago motivado por dificultades organizativas y de gestión que condicionan la movilidad de manera análoga a otros tipos de servicios de costosa implementación. Lo que sí queda establecido es que la Iglesia católica no sigue lineamientos establecidos para la localización de templos de oración.

Los estratos de población que presentan mayores niveles de pobreza han abandonado el credo católico en razón de la pertinencia de las religiones evangélicas para abordar problemas tales como el acceso a una salud mental y corpórea de calidad, la mejora en la calidad (y en el nivel) de vida individual y familiar mediante mecanismos doctrinales que apuntan a un cambio en la conducta de las personas.

La modalidad de crecimiento de la ciudad de Santiago ha generado, entre otras consecuencias, la ocupación de espacios para fines residenciales que inhiben la ocupación de suelo para el levantamiento de templos católicos, cuestión que no afecta a los credos evangélicos, que pueden ocupar casas u otros espacios con mayor libertad.

Este trabajo buscó aportar al catastro y conocimiento de la distribución de los creyentes católicos a una escala micro, así como al comportamiento socioespacial de los grupos dentro del AMS en las últimas décadas. Al mismo tiempo, la relación de lo anterior con el estudio de la presencia espacial de la Iglesia católica en la infraestructura urbana permitió detectar puntos a los que podrían dirigirse planes, programas y proyectos destinados a lograr un acercamiento más eficaz de la Iglesia a la comunidad. Se buscó relacionar la actual geografía socioeconómica con la presencia de la Iglesia como agente urbano, distinguiendo las tendencias actuales, así como las concordancias y las discrepancias que se generan en el actuar de la Iglesia y de los creyentes en la ciudad. OEURE 


\section{Referencias bibliográficas}

Allerton, C. (2009). Introduction: Spiritual landscapes of Southeast Asia. Anthropological Forum, $19(3), 235-251$.

Berger, P. (2005). Pluralismo global y religión. Estudios Públicos, 98, 5-18.

Bothner, M. (1994). El soplo del Espíritu: perspectivas sobre el movimiento pentecostal en Chile. Estudios Públicos, 55, 261-296.

Cabrales, L. (2002). Latinoamérica: paises abiertos, ciudades cerradas. Guadalajara: Unesco/Universidad de Guadalajara.

Castells, M. (1975). La cuestión urbana. Madrid: Siglo XXI Editores.

Centro de Investigaciones Socioculturales (Cisoc)-Bellarmino (1999). La parroquia en América Latina. Resumen marzo. Santiago: Cisoc. En http://www.cisoc.cl/html/marzo.html

Champion, F. (1997). Lo religioso flotante, eclecticismo y sincretismos. En J. Delumeau, El hecho religioso (una enciclopedia de las religiones hoy) (pp. 535-557). México D.F.: Siglo XXI Editores.

Código de Derecho Canónico (1983). Código de Derecho Canónico promulgado por la autoridad de Juan Pablo II, Papa. Roma: Vaticano.

Conferencia Episcopal de Chile (2008). Glosario de términos religiosos y eclesiásticos. Documento para periodistas. Santiago de Chile: Oficina de Comunicaciones y Prensa Conferencia Episcopal de Chile.

Cosgrove, D. (1988). The iconography of landscape: Essays on the symbolic representation, design and of past environments. Cambridge: Cambridge University Press.

Cosgrove, D. (1998). Social formation and symbolic landscape. Madison, WI: University Wisconsin Press.

Dando, W. (2009). A Review of "The Geography of Religion: Faith, Place, and Space". The Professional Geographer, 61(4), 567-568. doi:10.1080/00330120903103213

Dewsbury, J. D. (2009). Spiritual landscapes: Existence, performance and immanence. Social \& Cultural Geography, 10(6), 695-711.

Flores, F. (2007). ¿De qué hablamos cuando hablamos de geografía cultural? Un balance historiográfico. Interpretaciones. Revista de historiografía americana, 2, 4-21.

Fontaine, A. \& Bayer, H. (1991). Retrato del movimiento evangélico a la luz de las encuestas de opinión pública. Estudios Públicos, 44, 1- 52.

Gaete, A. (1986). Iglesias y ciudades evolucionan juntas. Revista de Geografia Norte Grande, 13, 59-67.

Galilea, C. (1987). Lugares de culto religioso en Santiago. Distribución, población y perspectivas. Santiago: Centro de Investigaciones Socioculturales (Cisoc)-Bellarmino.

Gökariksel, B. A. (2009a). New transnational geographies of Islamism, capitalism and subjectivity: The veiling-fashion industry in Turkey. Area, 41(1), 6-18.

Gökariksel, B. A. (2009b). Beyond the officially sacred: religion, secularism, and the body in the production of subjectivity. Social \& Cultural Geography, 10(6), 657-674.

Gourou, P. (1936). Les paysans du delta tonkinois, étude de géographie humaine. París: Éditions d'Art et d'Historie.

Henn, A. (2008/2009). Crossroads of religions: Shrines, mobility and urban space in Goa. International Journal of Urban \& Regional Research, 32(3), 658-670. doi:10.1111/j.14682427.2008.00803.x 
Hidalgo, R. \& Borsdorf, A. (2005). Megaproyectos residenciales vallados en la periferia: ¿barrios cerrados autosuficientes o nuevas ciudades? Urbano, 8 (12), 5-12.

Hidalgo, R. (2005). La vivienda social en Chile y la construcción del espacio urbano en el Santiago del siglo XX. Santiago: Instituto de Geografía, P. Universidad Católica de Chile/Centro de Investigaciones Diego Barrios Arana.

Holloway, J. (2006). Enchanted spaces: The séance, affect, and geographies of religion. Annals of the Association of American Geographers, 96(1), 182-187. doi: 10.1111/j.14678306.2006.00507.x

Hourtart, F. (1997). Religión, sociedad y mercado en el neoliberalismo (tres ensayos). México D.F.: Centro de Investigaciones Interdisciplinarias en Ciencias y Humanidades-Universidad Nacional Autónoma de México (UNAM).

Ivakhiv, A. (2006). Toward a geography of "Religion": Mapping the distribution of an unstable signifier. Annals of the Association of American Geographers, 96(1), 169-175. doi: 10.1111/j.14678306.2006.00505.x

Juan XXIII (1962). Gaudet Mater Ecclesia. Discurso durante la inauguración del Concilio Vaticano II. El Vaticano 11 de octubre de 1962. En http://www.mercaba.org/JUAN\%20XXIII/gaudet_mater_ecclesia.htm

Kong, L. (1990). Geography and religion: Trends and prospects. Progress in Human Geography, 14(3), $355-371$.

Lehmann, C. (2001). ¿Chile un país católico? Puntos de Referencia [Centro de Estudios Públicos, Edición online], 249. En http://www.cepchile.cl/dms/archivo_2980_472/pder249_lehmann.pdf

Lehmann, C. (2002). ¿Cuán religiosos somos los chilenos? Mapa de la religiosidad en 31 países. Estudios Públicos, 85, 21-40.

Lehman, C \& Hinzpeter, X. (1999). Mapa de la religiosidad. ¿Cuán religiosos somos los chilenos? Estudios Públicos, Verano de 1999 (73), 1-11.

León XIII (1891).Encíclica Rerun Novarum. En http://www.vatican.va/holy_father/leo_xiii/encyclicals/documents/hf_l-xiii_enc_15051891_rerum-novarum_sp.html

Martorini, J.; Hoberg, K. (2004). Indicadores cuantitativos de segregación residencial. El caso de la población inmigrante en Barcelona. Revista Electrónica de Geografia y Ciencias Sociales. Scripta Nova, 8(169). En http://www.ub.es/geocrit/sn/sn-169.htm

Pickard, S. (2009). Church of the in-between God: Recovering an ecclesial sense of place down-under. Journal of Anglican Studies, 7(1), 35-54.

Pontificia Universidad Católica de Chile (PUC)-Adimark (2008). Encuesta Bicentenario. Santiago: Autor.

Sabatini, F.; Cáceres, G.; Cerda, J. (2001). Segregación residencial en las principales ciudades chilenas: Tendencias de las tres últimas décadas y posibles cursos de acción. EURE, 27(82), 21-32. doi: $10.4067 /$ S0250-71612001008200002

Salas, R. (1967). Geografía de la religión en la ciudad de Santiago. Memoria para optar al título de profesor de Historia y Geografía en la Universidad de Chile, Santiago.

Santos, M. G. M. P. (2008). Os santuários como lugares de construção do sagrado e de memória hierofânica: esboço de uma tipologia. En Z. Rosendahl \& R. Lobato (Orgs.), Espaço e cultura: pluralidade temática (pp. 79-107). Río de Janeiro, Brasil: Universidade do Estado do Rio de Janeiro (UERJ). 
Sopher, D. E. (1967). Geography of religions. Englewood Cliffs, NJ: Prentice-Hall.

Sopher, D. E. (1981). Geography and religion. Progress in Human Geography, 5, 510-524.

Stump, R.. (2008). The geography of religion: Faith, place and space. Lanham, MD: Rowman \& Littlefield.

Suárez, H. (2003). La religión en la sociedad red: la experiencia latinoamericana. En F. Calderón (Coord.), ¿Es sostenible la globalización en América Latina? Debates con Manuel Castells (Vol. II, Nación y cultura. América Latina en la era de la información, pp. 101-125). Santiago: Fondo de Cultura Económica (FCE)/Programa de Naciones Unidas para el Desarrollo (PNUD).

Tincq, H. (1997). La escalada de los extremismos religiosos en el mundo. En J. Delumeau (Ed.), El hecho religioso (una enciclopedia de las religiones para el mundo de hoy) (pp. 515-533). México D.F.: Siglo XXI Editores.

Touraine, A. (1988). La parole et le sang. Politique et société en Amérique Latine. París: O. Jacob.

Warf, B. \& Vincent, P. (2007). Religious diversity across the globe: A geographic exploration. Social \& Cultural Geography, 8(4), 597-613.

Warf, B. \& Winsberg, M. (2008). The geography of religious diversity in the United States. The Professional Geographer, 60(3), 413-424. doi: 10.1080/00330120802046786 